\title{
Debate actual da secularização: teorias adeptas versus teorias adversárias
}

\section{Current debate on secularisation: adept theories versus opponent theories}

\author{
José Pereira Coutinho*
}

\begin{abstract}
Resumo
Este artigo tem como objectivo organizar as teorias da secularização de forma diferente, assentando-as em filiações filosóficas/sociológicas e em níveis de análise. Para tal, como método, usa-se a análise comparada de conteúdo das teorias e/ou dos trabalhos mais relevantes dos principais autores. As teorias podem dividir-se em dois grupos principais, adeptos e adversários da secularização. Enquanto os adeptos se afiguram como aprofundamentos e ajustamentos das teorias clássicas à realidade contemporânea, advogando sobretudo a religiosidade individual, os adversários apresentam concepções diferentes das teorias clássicas da secularização, defendendo a permanência da religiosidade institucional. No primeiro grupo encontram-se as teorias pós-clássicas e as teorias da individualização, enquanto no segundo grupo apresentam-se o modelo económico, as teorias do regresso e as teorias histórico-culturais. Weber e Durkheim, e as correntes epistemológicas que representam, são a maior influência das várias teorias existentes, umas mais descendentes do primeiro, outras do segundo. 0 modelo económico distingue-se das restantes teorias por ser a única que não é influenciada por Weber e que é influenciada pelo empirismo anglo-saxónico.
\end{abstract}

Palavras-chave: secularização, teorias adeptas, teorias adversárias, Weber, Durkheim.

\begin{abstract}
This article aims to organise the theories of secularisation differently, based on philosophical/sociological affiliations and levels of analysis. To do so, as method, the comparative content analysis of the theories and/or the most relevant works of the main authors is used. Theories can be divided into two main groups, adepts and opponents of secularisation. While the adepts appear as deepening and adjustments of classic theories to the contemporary reality, advocating mainly the individual religiosity, the opponents present different conceptions of classic theories of secularisation, defending the permanence of the institutional religiosity. In the first group are the post-classical theories and the theories of individualisation, while in the second group are presented the economic model, the theories of return and the historical-cultural theories. Weber and Durkheim, and the epistemological schools they represent, are the major influence on the various existing theories, some mainly descendants of the former, others of the latter. The economic model differs from the other theories because it is the only one that is not influenced by Weber and is influenced by Anglo-Saxon empiricism.
\end{abstract}

Keywords: secularisation, adept theories, opponent theories, Weber, Durkheim.

Artigo submetido em 13 de junho de 2017 e aprovado em 28 de abril de 2018.

Doutorado em sociologia pelo ISCTE-IUL (Lisboa). Investigador da Númena - Centro de Investigação em Ciências Sociais e Humanas (Portugal). País de origem: Portugal. E-mail: jose.coutinho@numena.org.pt

Horizonte, Belo Horizonte, v. 16, n. 49, p. 326-355, jan./abr. 2018 - ISSN 2175-5841 


\section{Introdução}

As teorias da secularização enformam a análise sociológica da evolução religiosa no mundo ocidental, reflectindo as perspectivas sobre a modernização, desde as origens da sociologia até à actualidade. Nos anos 1960 surgiram as teorias clássicas, sobretudo de Berger, Luckmann e Wilson, embora o seu domínio durasse pouco, pois as especulações teóricas associadas tanto à realidade norte-americana como a vários casos empíricos de ressurgimento ou de persistência religiosa, tornaram inadequadas as teorias clássicas, obrigando a repensá-las. Já as teorias clássicas, quando foram desenvolvidas, assinalavam-se pela revolta contra a situação sociológica na altura (TSCHANNEN, 1992, p. 294), forçando porventura os sociólogos a extremar as suas posições. Desta forma, a maioria das teorias subsequentes conduzir-se-ia pela moderação em relação à religião, não só porque a afirmação de determinado grupo deixara de fazer sentido, mas também porque as críticas recebidas impuseram limites.

No debate em torno da secularização, para além do modelo económico e das teorias da secularização, estas divisíveis em clássicas e modificadas (WARNER, 2010), nas quais se enquadram sobretudo as teorias da individualização (POLLACK et al., 2012), podem incluir-se ainda as múltiplas secularizações ( Beck, 2010) ou o conflito sociopolítico (GORSKI, 2003). No entanto, considero que a variedade de contributos obriga à existência de uma divisão diferente. Este artigo pretende organizar então em grupos homogéneos os vários contributos produzidos nas últimas décadas, uns mais teóricos e outros mais empíricos, e apresentar os mais relevantes. Para tornar mais consistente a organização, os contributos serão ainda classificados por filiação sociológica/filosófica, algo que não tenho visto noutros trabalhos, para além dos níveis de análise.

$\mathrm{Na}$ minha perspectiva, considero que as teorias se dividem em dois grupos principais, adeptos e adversários da secularização. Enquanto os adeptos se afiguram como aprofundamentos e ajustamentos das teorias clássicas à realidade 
contemporânea, advogando sobretudo a religiosidade individual, os adversários apresentam concepções diferentes das teorias clássicas da secularização, defendendo a permanência da religiosidade institucional. Estes dois grupos poderiam denominar-se também teorias da religiosidade individual versus teorias da religiosidade institucional, teorias da privatização versus teorias da pluralização, ou teorias da autonomia versus teorias da pertença.

Infelizmente as limitações de espaço proíbem a discussão. Esta análise cinge-se ao mundo ocidental, onde nasceu a sociologia e a secularização, focandonos nas teorias que analisam a sua evolução religiosa. Vários autores têm contribuído para este debate. No entanto, sendo o espaço limitado, cinjo-me tanto aos contributos mais relevantes como a sociólogos da religião, sendo Inglehart, Bell e Taylor as únicas excepções, referidos pela importância dos seus contributos na época ou actualmente. Ressalve-se que as teorias dos autores não são declarações de fé, agnosticismo ou ateísmo, mas simplesmente formas de tentar explicar ou compreender a realidade.

\section{Teorias adeptas da secularização}

Neste grupo incluem-se dois subgrupos. As teorias pós-clássicas continuam as teorias clássicas, abordando os três níveis (micro, meso e macro), enquanto as teorias da individualização aprofundam o seu nível micro. Embora com abrangências distintas, elas partilham o foco na privatização e por isso na religiosidade individual, desconexa das ligações institucionais. Mesmo que se analise a relação do indivíduo com a religião formal, as teorias tentam explicar a forma como a pessoa decide a pertença a determinada religião, claro por exemplo em Hervieu-Léger ou Davie. A grande questão passa pela autonomia pessoal, fruto das sociedades pós-industriais ocidentais, que catalisou a liberdade de escolha e, por isso, a independência nas opões religiosas. 


\subsection{Teorias pós-clássicas}

Neste subgrupo encontram-se os contributos que continuam e sintetizam as teorias clássicas, destacando-se Olivier Tschannen (1958), Karel Dobbelaere (1933), Mark Chaves (1960) e Steve Bruce (1954). Inglehart desenvolveu uma teoria que poderia ser incluída aqui (Norris e Inglehart, 2004), mas como apresentou outra (Inglehart e Welzel, 2005), enquadrável nas teorias da individualização, faz mais sentido apresentá-las juntas nesse subgrupo. Refira-se que neste subgrupo pertencem não só sociólogos europeus (TSCHANNEN, DOBBELAERE, BRUCE) como também sociólogos norte-americanos (CHAVES, YAMANE, INGLEHART), o que demonstra a existência de defensores da secularização também do outro lado do Atlântico.

O primeiro contributo vem de Tschannen (1991), o qual resumiu as teorias clássicas num complexo teórico, assente na perspectiva de Kuhn, a que denominou de paradigma da secularização, no qual os conceitos partilhados contribuem para interpretar a situação religiosa de forma igual. Tschannen (1991, p. 400-402) sintetiza as proposições teóricas clássicas Berger (1967), Luckmann (1967) e Wilson (1966), assim como de outros autores (MARTIN, 1969; FENN, 1970; PARSONS, 1963; e BELLAH, 1967), assente em dois pressupostos e três conceitos. Os dois pressupostos são: as raízes da secularização encontram-se na própria religião (raízes religiosas) e a imanência da religião à condição humana leva-a a nunca desaparecer (permanência). Os três conceitos são: diferenciação, em que a religião emerge diferenciada de outros domínios sociais; racionalização, em que deste processo de diferenciação as instituições não religiosas trabalham com base em critérios racionalmente relacionados com as funções sociais específicas fora do controlo religioso; e mundanização, em que a religião atravessada pela racionalização perde alguma da sua especificidade, tornando-se mais profana, mais deste mundo. A diferenciação tem as seguintes consequências: autonomização das instituições em relação à religião, que perde o seu poder de controlo social e de guia social; privatização da religião, em que o indivíduo passando pelas esferas 
sociais com visões do mundo diferentes e incompatíveis tem de construir a sua interpretação do mundo, que pode incluir religião personalizada; generalização da religião, em que esta se espalha disfarçadamente pelos vários domínios sociais; pluralização religiosa, em que com o colapso do monopólio religioso aparecem várias denominações em competição; declínio na prática, pela quebra do controlo social das igrejas. A racionalização tem duas consequências: cientização, em que a ciência desenvolve uma visão do mundo diferente da religiosa, entrando em competição; sociologização, em que se tenta determinar a vida social racionalmente sem influência religiosa. O colapso da visão do mundo e a descrença manifestam a cientização e a pluralização em níveis diferentes: no nível societal, as visões do mundo perdem a sua plausibilidade, enquanto, que, no nível individual, a crença declina. A sociologização e o declínio na prática não pertencem totalmente ao paradigma, por serem os seus elementos mais fracos, pouco reconhecidos pelos autores, sendo essenciais nas abordagens precedentes: o primeiro, central ao positivismo do século XIX, de Comte e Spencer, que preconizavam a substituição da religião pela ciência, e o segundo, fulcral à sociologia religiosa católica europeia dos anos 1930 aos anos 1960.

Dobbelaere (1999), conjugando a sua análise tridimensional (nível macro, meso e micro), usada em Dobbelaere (1981), com o paradigma de Tschannen (1991), acima referido, apresenta o paradigma da secularização em três níveis. Tal como Tschannen (1991), baseia-se sobretudo nos três autores (WILSON, BERGER e LUCKMANN) e nos mesmos conceitos, embora redenominando alguns. Para Chaves (1994, p. 757), esta construção teórica tridimensional da secularização é a mais bem desenvolvida e influente, e, para Willaime (2006, p. 764), a vantagem desta perspectiva tridimensional é mostrar que a secularização não é um processo unilinear conducente ao declínio geral da religião, mas algo mais complexo, analisável em três níveis com alguma independência, ou seja, em que a secularização num não implica a sua existência noutro. 
Vejamos então a proposta de Dobbelaere (1981, p. 11-12; 1999, p. 230-241). No nível macro ou societal domina o processo de laicização, no qual, com a diferenciação institucional, a religião é uma instituição como as outras perdendo o seu papel preponderante, transpondo-se as funções antes exercidas pela religião para a sociedade. A diferenciação produziu diferentes subsistemas, cada com os seus valores e normas próprios, em autonomização do subsistema religioso; a geração de subsistemas autónomos permitiu o desenvolvimento da racionalização, dando espaço ao domínio da ciência e da técnica nos mesmos; o mundo racionalizado gerou o seu desencantamento, ou seja, calculável e construído pelo homem, resultado de planeamento controlado; ao mesmo tempo, gerou-se a societalização, com o aparecimento de relações pessoais despersonalizadas, baseadas não na pessoa mas no papel por ela desempenhado; a diferenciação e a autonomização causaram a privatização, a existência da religião somente na esfera privada. No nível meso ou subsistémico domina o processo de mudança religiosa, havendo pluralização, derivada da diferenciação segmentária do subsistema religioso, que gerou mercado religioso, no qual as várias denominações competem pelas almas, levando à relativização dos conteúdos religiosos e, assim, à crise de credibilidade religiosa; muitas denominações actuais perderam a noção de transcendência, preocupando-se, principalmente, com a resolução dos problemas pessoais, tornando-se mundanas. No nível micro ou individual domina o processo de envolvimento religioso, que se refere à influência das normas religiosas sobre as atitudes e os comportamentos individuais, havendo declínio religioso ou descristianização. A privatização provocou a individualização, na qual os indivíduos, ao escolherem a sua comunidade de amor, experimentam a alegria da pertença; a perda da autoridade da Igreja, a pluralização e a individualização levaram à bricolage religiosa, não sendo aceite o menu das igrejas, mas antes construída individualmente "religião à carta", misturando doutrinas e desenvolvendo crenças heterodoxas e vários graus de crença e descrença; com a diminuição da crença num Deus pessoal, os rituais cristãos são abandonados, uma vez que se baseiam nesta premissa, diminuindo a participação na igreja. 
A proposição de Dobbelaere (1981) foi reformulada por Chaves (1994, p. 757), o qual referiu que “a secularização é melhor compreendida não como declínio da religião mas como o alcance decrescente da autoridade religiosa”, compreendida em três dimensões: no nível societal, a incapacidade crescente das elites religiosas em exercer autoridade sobre outras esferas institucionais; no nível organizacional, o declínio do controlo da autoridade religiosa sobre os recursos organizacionais na esfera religiosa; no nível individual, o decréscimo do controlo religioso nas acções individuais. Na senda deste autor, Yamane (1997, p. 109) cunhou o termo neosecularização para designar uma nova teoria da secularização, baseada na antiga mas incorporando os criticismos, tendo como coração a tese de que a secularização significa não a quebra da religião mas da autoridade religiosa no nível societal, organizacional e individual.

Bruce desenvolve os seus contributos sobretudo em dois livros (Bruce, 1996, 2002). Na linha de Wallis, Bruce (1996, p. 4-5) descreve a evolução religiosa no mundo ocidental desde a Reforma, considerando que as formas organizacionais dominantes se foram alterando: a igreja no período medieval, a seita na Era Moderna, a denominação no século XX e o culto no século XXI. O declínio das tradições principais deu espaço a novas religiões e a inovações tipo Nova Era, mas, embora estas chamem a atenção, o seu impacto social é pequeno. O baixo número de pessoas envolvidas é composto de pessoas bastante exigentes, que se caracterizam pelo individualismo actual, escolhendo as opções religiosas que melhor se encaixam na sua personalidade, desejos e necessidades, sendo verdadeiro somente o que funciona para cada indivíduo, em total relativismo. Noutro livro, Bruce (2002, p. 3-30) defende que a secularização ocorre em três níveis (societal - autonomização, organizacional - privatização, individual - declínio de práticas, crenças e atitudes) e se esquematiza em quatro colunas com vários processos sucessivos, na linha de Weber, Wilson, Berger. Resumindo, o grande motor da secularização é a Reforma, da qual partem todas as colunas, mesmo a primeira, pois a racionalidade e a ciência derivam dela. A primeira linha refere-se à racionalização, não só por ser a mais importante como a mais antiga, começando 
no monoteísmo e terminando na consciência tecnológica. A segunda linha inicia no individualismo, culminando na literacia e associações voluntárias. A terceira linha começa na diferenciação social, terminando no relativismo. A quarta linha inicia na diferenciação estrutural, culminando na compartimentação e privatização.

\subsection{Teorias da individualização}

Como vimos em cima, sendo as teorias da individualização sucessoras das teorias clássicas, as suas raízes encontram-se tanto no positivismo francês como no idealismo alemão. Estas teorias partilham o foco no nível micro, com a centralidade do indivíduo em detrimento das instituições religiosas (religiosidade como estado interior em Simmel, misticismo como experiência individual em Troeltsch, religião como experiência individual em James) e a bricolage religiosa, desenvolvida por Luckmann, no seguimento sobretudo de Durkheim e no âmbito da quarta forma social de religião (religião invisível). Durkheim enquadra-se na escola positivista francesa, enquanto os outros surgem da escola idealista alemã, mesmo James, já que o seu pragmatismo entronca no transcendentalismo de Emerson, por sua vez herdeiro do idealismo alemão. Do lado americano apresenta-se Ronald Inglehart (1934) e Wade Roof (1939); do lado inglês afiguram-se Grace Davie (1946) e Paul Heelas (1946); por último, do lado francês surge Danièle Hervieu-Léger (1947).

Inglehart apresenta duas propostas teóricas: o modelo da segurança existencial, relacionado com a passagem de sociedades tradicionais para sociedades industriais; a dicotomia materialismo vs pós-materialismo, relativo à passagem de sociedades industriais para sociedades pós-industriais. O modelo da segurança existencial lançado por Norris e Inglehart (2004, p. 217-235), influenciado por Weber e Huntington, baseia-se em dois axiomas e cinco hipóteses centrais. No axioma da segurança, as sociedades, ao divergirem nos seus níveis de desenvolvimento económico e humano e na igualdade socioeconómica, providenciam segurança existencial diversa às pessoas. Este axioma induz a hipótese dos valores religiosos a sustentar que as condições experimentadas pelas 
pessoas nos primeiros anos de vida têm impacto profundo nos seus valores culturais: em ambientes incertos a religião fortalece-se; pelo contrário, em contextos seguros, ocorre o declínio religioso. No axioma das tradições culturais, as crenças, valores e práticas religiosas predominantes em qualquer sociedade estão enraizadas em tradições religiosas, influenciando os seus membros, mesmo quando eles não pertencem à denominação principal. Este axioma conduz à hipótese das culturas religiosas: embora níveis crescentes de segurança levem à secularização, a tradição religiosa predominante numa sociedade tende a deixar impacto duradouro em crenças religiosas e em atitudes morais. Da conjugação das hipóteses dos valores e das culturas, surge a hipótese da participação religiosa, a prever que os valores e as crenças religiosos influenciam largamente as práticas religiosas. Este modelo tem de se conjugar com a dicotomia materialismo vs pós-materialismo (INGLEHART e WELZEL, 2005, p. 26-33), influenciada por Durkheim (passagem da solidariedade mecânica para a solidariedade orgânica), Tönnies (passagem de comunidades para sociedades) e Simmel (diversificação das interacções sociais), na medida em que explicam a autonomia pessoal. Enquanto na fase pré-industrial e industrial os riscos habituais, a fome e a escassez económica eram concretos e imediatos, na fase pós-industrial os riscos são abstractos, não sendo imediatamente sentidos, mas tendo de ser compreendidos e por vezes discutidos. A libertação dos riscos imediatos permite a preocupação por ameaças mais diferidas, passando-se do foco de valores materialistas, ligados à segurança física e económica, para valores pós-materialistas, associados à livre expressão individual e a preocupações políticas e ambientais. Neste âmbito, desenvolve-se a individualização religiosa, na qual da institucionalização religiosa se passa a formas flexíveis, personalizadas, assentes na auto-expressão e na busca de sentido.

Roof desenvolve os seus contributos sobretudo em dois livros (ROOF, 1993, 1999), na linha de William James e dos seus estudos tipológicos. Roof (1993)² estudou a geração pós-guerra assente numa amostra de mais de 2.500 pessoas de

\footnotetext{
${ }^{2}$ Informação sobre este livro consultada em The New York Times:

http://www.nytimes.com/1993/05/30/weekinreview/conversations-wade-clark-roof-charting-currents-belief-for-generation-that.html
} 
quatro estados norte-americanos, escolhidos por representarem as várias realidades nacionais. A amostra dividiu-se em 58\% de praticantes, $28 \%$ de crentes mas não pertencentes, $9 \%$ de buscadores e $5 \%$ de ateus ou agnósticos. Dos dois terços que abandonaram as suas organizações religiosas, dois quintos voltaram na meia-idade, embora não necessariamente à religião organizada. Resumindo, esta geração procura o calor, as emoções, a identidade e a experimentação, daí a sua busca fluida. No segundo livro, assente na mesma metodologia e amostra da geração pós-guerra, Roof (1999, p. 9-10) demonstra que as fronteiras das comunidades religiosas estão em redefinição, devido à cultura da procura e da reflexividade espirituais desta geração, o que é facilitado pelo crescente mercado espiritual. Para Roof há cinco subculturas religiosas (dogmáticos, cristãos renascidos, crentes normais, crentes e buscadores metafísicos, e secularistas), as quais estão em constante formação de identidade, reformulando assim permanentemente o mercado espiritual (MARKULY, 2002). Os cristãos renascidos é a maior subcultura, dando o maior contributo para o mercado espiritual, pela ligação única entre crença teológica tradicional, sensação corporal e experiência religiosa, apesar do seu pluralismo interno. Os crentes normais, a segunda maior subcultura, caracterizada pela 'normalidade' das suas vidas, contribuem para a pluralidade do mercado espiritual, por se sentirem mais próximos dos descrentes e por procurarem orientação espiritual fora das organizações religiosas. Os crentes e buscadores metafísicos são os que têm concorrido mais para a quebra da religiosidade tradicional norte-americana, colocando ênfase no corpo ainda maior do que os cristãos renascidos e estando em permanente mudança de identidade religiosa, o que dá a sensação de fluidez do mercado espiritual. As outras duas subculturas são marginais.

Davie tem contribuído para a análise da relação entre religião e modernidade sobretudo na Europa e na Grã-Bretanha. Publicou dois estudos (DAVIE, 1994, 2015), nos quais analisa esta relação para a Grã-Bretanha, obviamente com claras extrapolações para a Europa, até porque os factores considerados foram utilizados noutros estudos sobre este continente (DAVIE, 
2006). Os factores considerados na análise desta relação são: papel das igrejas históricas na geração da cultura, consciência do papel das mesmas na vida das pessoas, mudança das formas de participação religiosa assentes mais na escolha do que no dever, entrada de grupos diversos com diferenças religiosas em relação ao país hospedeiro, reacção das elites seculares à crescente saliência da religião na vida pública e privada, consciência crescente da excepcionalidade da Europa em termos religiosos (DAVIE, 2015, p. 3-4; 2006, p. 271-272). Relativamente à individualização, as suas teses assentam em dois conceitos, referentes ao segundo factor acima referido, crença sem pertença e religião vicária, o primeiro surgido em Davie (1994) e o segundo em Davie (2000), baseado na tese da religião como memória de Hervieu-Léger e portanto na linha francesa de Durkheim. Com o primeiro conceito a autora pretendia ilustrar a diferença de decréscimo entre os indicadores 'duros' e 'suaves' da religiosidade: enquanto a prática decresce claramente, a crença parece manter-se relativamente forte (DAVIE, 2015, p. 5). Contudo, este conceito trouxe-lhe dúvidas, sobretudo por separar dois tipos de religiosidade, surgindo então o segundo conceito, em que uma minoria activa acredita, pratica e segue padrões morais em nome da maioria passiva, que aprova o que aquela faz, para além das igrejas serem espaços de debate em questões actuais (DAVIE, 2015, p. 6).

Heelas tem estudado a espiritualidade numa vertente mais antropológica, dedicando bastante tempo a trabalho de campo, sobretudo na Ásia, sendo observador participante do surgimento das espiritualidades da vida desde os anos 1960, influenciado certamente pelas experiências do seu conterrâneo Aldous Huxley (1894-1963), e pelas concepções teóricas de Simmel (religiosidade) e Troeltsch (misticismo). Numa trilogia escreveu sobre as trajectórias de espiritualidades alternativas ou Nova Era (HEELAS, 1996; HEELAS e WOODHEAD, 2005; HEELAS, 2008). No primeiro livro, Heelas (1996, p. 3-4) aborda a Nova Era, defendendo que, apesar da sua diversidade, assenta na espiritualidade do self, na sua sacralidade, considerando que todas as pessoas são deuses, pelo que a felicidade pessoal passa pelo encontro e da abertura para fora do 
que está dentro de si. No segundo livro, Heelas e Woodhead (2005, p. 10) defendem a ideia de que o laço histórico entre cultura ocidental e cristianismo, caracterizado pela autoridade transcendental, está rapidamente em dissolução, estando em seu lugar a surgir uma situação menos regulada, em que o sagrado é experienciado em relações íntimas com o self próprio. No terceiro livro, Heelas (2008, p. x), ultrapassando a noção de espiritualidades de self, abordadas nos livros anteriores, desenvolve a ideia das espiritualidades da vida e da sua relação com o consumo, na medida em que marcam a cultura do bem-estar subjectivo, exemplo maior da cultura consumista. Heelas começa por defender, ao contrário de outros, que a Nova Era encontra as suas raízes na ética humanista do Iluminismo e na ética expressionista do Romantismo, as quais, em vez de se oporem, contrabalançam-se, reforçando as espiritualidades da vida (Heelas, 2008, p. 30). Como tese principal, Heelas (2008, p. 4-7) refuta a ideia de que a Nova Era reforça o consumismo capitalista e o individualismo romântico, defendendo que, pelo contrário, combate esta tendência e responde aos males daqueles, sendo melhor do que as religiões tradicionais.

Para Hervieu-Léger (2000, p. 123-125), a modernidade, pela mudança que a caracteriza, dificulta paulatinamente a existência das comunidades religiosas ou linhagens crentes, pois estas formam-se e reproduzem-se pela manutenção da memória colectiva religiosa, ligando ininterruptamente os crentes actuais aos do passado e do futuro, como cadeias de memória, algo decorrente da anamnese, da recordação do passado, sobretudo através dos ritos. Esta teorização assenta duplamente em Durkheim, tanto indirectamente, pela tese da memória colectiva de Maurice Halbwachs (1950), que por sua vez se baseia no conceito de representação colectiva de Durkheim (2001, p. 18), como directamente, pela consideração da importância central do rito na preservação da ordem social (DURKHEIM, 2001, p. 312-314). Seguindo a proposta da modernidade tardia de Giddens, imbuída de risco, a autora considera que os indivíduos se encontram à deriva, privados da segurança das comunidades estáveis tradicionais, procurando acima de tudo a sua realização pessoal (HERVIEU-LÉGER, 200o, p. 165-166). Desta forma, a escolha 
deliberada de reconhecer a autoridade de uma tradição religiosa, incorporando-se numa linhagem crente, torna-se modo pós-tradicional de construir a identidade pessoal, enquadrada pela busca comunitária, pela demanda de sentido e pela fragmentação das experiências. Retomando esta perspectiva, noutro livro, HervieuLéger (2005, p. 31, 47-52) pretende compreender as recomposições religiosas, suportando a sua abordagem no conceito de bricolage, assente em Luckmann (1970, p. 98-99). A construção individual da continuidade crente ou a pertença a determinada linhagem crente resulta de trajectórias de identificação assentes em várias dimensões (comunitária, ética, cultural e emocional), enquadradas em contextos socioculturais e em histórias de vida particulares (HERVIEU-LÉGER, 2005, p. 69-83). Para caracterizar a religiosidade da nossa modernidade, HervieuLéger (2005, p. 91-128) usa três ideais tipos: o praticante, símbolo da religiosidade tradicional, que pratica de forma obrigatória, institucional e fixa; o peregrino, símbolo da mobilidade religiosa actual, que pratica de forma voluntária, autónoma e moldável; o convertido, símbolo da formação das identidades religiosas actuais, que define a sua identidade de acordo com a sua história, desdobrando-se em três tipos (os que mudam de religião, os sem religião que aderem a determinada religião, os que redescobrem a sua religião formal).

\section{Teorias adversárias da secularização}

No segundo grupo incluem-se três subgrupos: o modelo económico e as teorias do regresso, ambos associados aos EUA e surgidos nos anos 1970, e as teorias histórico-culturais, que foram ganhando maior peso nos últimos anos, na senda das múltiplas modernidades. O modelo económico centra-se nos níveis micro e meso, as teorias do regresso nos três níveis e as teorias histórico-culturais nos níveis meso e macro. Estas teorias partilham o foco na religiosidade institucional à revelia das teorias clássicas da secularização, assentando sobretudo na questão da pluralização, especialmente no modelo económico e nas teorias histórico-culturais. As teorias do regresso congregam contributos, sobretudo norteamericanos, que não se inscrevem no modelo económico, também apostando na 
pluralização (Berger), no recuo da privatização (Casanova) ou na busca de sentido (Bell, Greeley), para explicar o dinamismo religioso institucional. A grande questão nestas teorias passa por explicar a pertença institucional contrariamente às teorias da secularização, como no modelo económico e nas teorias do regresso, ou a relação que a história e a cultura têm no grau de secularização, como nas teorias histórico-culturais.

\subsection{Modelo econômico}

Os sociólogos norte-americanos, adversários da teoria da secularização, desenvolveram uma alternativa designada por modelo económico, modelo das economias religiosas, novo paradigma ou novo voluntarismo, assinalada pela teoria da escolha racional. A secularização é vista como processo auto-limitado de curto prazo, pela procura permanente de sentido e de imortalidade, sendo o ambiente competitivo das sociedades modernas pluralistas mais religioso do que a idade da fé' pré-industrial, onde haveria apatia generalizada (ALDRIDGE, 2000, p. 95). Azzi e Ehrenberg (1975) realizaram o primeiro estudo de economia religiosa, no qual criaram um modelo económico de análise do comportamento religioso do agregado familiar, incluindo, entre outros, a participação religiosa segundo o ciclo de vida ou entre marido e mulher. Rodney Stark (1934), William Bainbridge (1940), Roger Finke (1954) e Laurence Iannaccone (1954) são os autores principais desta teoria, sendo os dois primeiros considerados por Aldridge (2000, p. 95) como a sua expressão mais forte. A genealogia deste modelo radica no empirismo britânico, nomeadamente no liberalismo de Adam Smith e no utilitarismo de John Stuart Mill, matriz da teoria da escolha racional. A escola francesa também influenciou este modelo, através do liberalismo de Tocqueville e do funcionalismo de Durkheim, este através de Parsons, o qual foi ainda marcado pelo marginalismo austríaco.

Para Adam Smith (1723-1790), 'teórico' do liberalismo económico, as organizações religiosas poderiam ser equiparadas às organizações seculares: a 
competição, o monopólio e a regulamentação governamental existem também na religião; as forças de mercado constrangem igualmente as igrejas; o clero move-se também pelo interesse próprio (IANNACCONE, 1991, p. 156). Realmente, em Smith (1902, p. 171-174), o empenho dos clérigos dependeria da origem da sua subsistência: se fosse estabelecida previamente, levaria ao descuido; se dependesse da vontade das comunidades, levaria ao zelo. No utilitarismo de Stuart Mill (18061873) aplica-se o princípio da maior felicidade, advogado de uma existência isenta de dor e rica na quantidade e na qualidade dos prazeres (KENNY, 1999, p. 366), mais tarde reformulado pela teoria da escolha racional, norteada pelo cálculo de recompensas e custos (SCOTT, 1997, p. 77). Para Alexis de Tocqueville (18051859), na América o espírito da religião e o espírito de liberdade estão intimamente ligados, o que induz a separação entre igreja e estado, a liberdade de consciência, de culto e de assembleia dos cidadãos e a pluralidade democrática das organizações religiosas (ALDRIDGE, 2000, p. 89-90). Como defendia Tocqueville (2008, p. 262263), a liberdade e a religião confundem-se no espírito americano: a religião regula os costumes, Talcott Parsons (1902-1979) desafia a teoria da secularização pelo seu 'velho' voluntarismo, considerando a religião como fundamento dos valores sociais últimos, dos quais derivam as regras, condutas e costumes sociais (ALDRIDGE, 2000, p. 91). No seguimento de Durkheim, Parsons (1952, p. 7-8) considera que a religião congrega as pessoas numa comunidade moral, pela partilha de crenças, práticas e valores comuns. Rejeita o desencantamento do mundo de Weber e Berger, encarando a diferenciação social como forma de fortalecimento religioso, por se libertar das outras esferas sociais, podendo dedicar-se exclusivamente à sua função capital, de fornecedora de sentido (ALDRIDGE, 2000, p. 91-92). Para Parsons (1952, p. 15), o problema religioso por excelência consiste na justificação dos actos de Deus, na compreensão da condição humana relativamente à ordem estabelecida pelo divino, em fornecer cosmovisão que faça sentido em termos intelectuais e emocionais. Da mesma forma, Parsons considerava o protestantismo não como porta para a secularização, como em Berger, mas como germe da iniciativa cristã no mundo secular (ALDRIDGE, 2000, p. 93). A separação da igreja e do estado associado à complexidade religiosa das treze colónias cristalizou o 
sistema pluralista, assente na tolerância total, como característica essencial da religiosidade americana (PARSONS, 1952, p. 35).

No seguimento de Parsons, o sociólogo norte-americano George Homans (1910-1989) desenvolveu a teoria da escolha racional no século XX, reformulando a teoria da acção de Parsons, enfatizando mais a acção em detrimento da estrutura, baseando-se também em Vilfredo Pareto (1848-1923) e no seu marginalismo (assente na utilidade marginal dos bens e assim na racionalidade e interesse próprio), inserido na revolução marginalista de Jevons, Walras e Menger (SCOTT, 1997, p. 73-74). Desta raiz norte-americana racionalista surge então o modelo económico, para o qual a acção humana se caracteriza essencialmente pela razão instrumental. Desta forma, a religião escolhe-se como qualquer outro produto, avaliando-se custos e benefícios, para maximizar os benefícios líquidos (IANNACCONE, 1995, p. 77). Os indivíduos procuram recompensas e evitam custos, mas, quando não as conseguem, podem aceitar compensadores, substitutos intangíveis daquelas, cujo valor depende da fé (STARK e BAINBRIDGE, 1996, p. 27, 36). Para algumas recompensas sobre o sentido último, como o sentido da vida, a morte ou o sofrimento, somente a religião consegue produzir compensadores credíveis, pois baseiam-se em suposições sobrenaturais, ao contrário do racionalismo científico ou do marxismo (STARK e BAINBRIDGE, 1996, p. 39-40). As organizações religiosas encontram-se assim em vantagem em relação às organizações mais secularizadas internamente, mais adaptadas ao mundo moderno, que deixaram de fornecer promessas transcendentais, pelo que a teoria da secularização se torna falsa, pois as pessoas procuram recompensas na religião (ALDRIDGE, 2000, p. 97). A vitalidade religiosa advém da estrutura livre, já que a competição estimula os fornecedores a produzirem fés alternativas bem adaptadas às necessidades dos consumidores, enquanto o monopólio patrocinado pelo Estado providencia apenas aparência de piedade, clero ineficaz e população apática (IANNACCONE, 1992, p. 128). A não regulação da economia religiosa permite maior pluralismo, expresso pelo número de firmas activas com quotas de mercado significativas, cujo sucesso depende da menor eficiência e variedade dos outros 
grupos religiosos existentes (STARK e FINKE, 2000, p. 198, 203). Nos mercados livres, as firmas religiosas têm de abandonar quer modos de produção ineficientes quer produtos pouco competitivos (IANNACCONE, 1995, p. 77), perdendo quota de mercado quando apresentam imagem mais distante e indistinta do sobrenatural, relaxam nas restrições morais e desvalorizam a verdade superior e exclusiva, apostolando menos (FINKE e STARK, 1989, p. 28).

\subsection{Teorias do regresso}

As teorias do regresso ou retorno do sagrado, ou da persistência da religião, não se apresentam como conjunto coerente de teorias, mas como apanhado de contributos díspares de vários sociólogos. Porém estes autores partilham a fé religiosa e a sua vivência nos EUA, que porventura influenciaram a sua visão optimista relativamente ao futuro da religião. Destes autores destacam-se Daniel Bell (1919-2011), judeu, norte-americano; Andrew Greeley (1928-2013), sacerdote católico, norte-americano; Peter Berger (1929), teólogo protestante, austríaco, a viver nos EUA desde os anos 1940; Jose Casanova (1951), católico, espanhol, a viver nos EUA desde os anos 1980. Nestas teorias denota-se influência não só de Weber, tanto na necessidade de permanência da religião pela busca do sentido (Bell, Greeley), como pela existência da pluralização (Berger), mas também de Durkheim no recuo da privatização da religião na esfera pública (Casanova).

Bell (1977, p. 442-447) defende o retorno do sagrado, pois a religião constitui a experiência humana, considerando-a, no seguimento de Walter Benjamin, a totalidade concreta da experiência, a que este autor chamou 'aura'. A destruição desta na cultura de elites conduziu à sua destruição na cultura de massas, tornando-se o ponto de partida para novas respostas religiosas, assentes na memória, tradição ou passado, as quais considera de três tipos. Primeiro: a religião moralizadora, estando as suas raízes e força numa fé fundamentalista contra os impulsos modernistas na política, sobretudo relativamente à vida e à sexualidade. Segundo: a religião redentora, em que, por um lado, em reacção aos excessos 
modernos, a religião se torna consciência de espaço de transcendência, em que a tradição mantém a continuidade dos significados morais, colocando-se as obrigações nos imperativos morais comunitários (educação e consciência moral); por outro lado, aparecem instituições mediadoras, centradas na noção de caridade e no cuidado pelos outros, contra a centralização governamental e as grandes organizações. Terceiro: a religião mística e mítica, na procura do sentido de maravilhoso e de mistério, em oposição à ciência e à monotonia, ou na busca da unificação do ser, assolado pelos seus dualismos.

Greeley propõe a tese da persistência da religião, considerando a secularização um mito (CIPRIANI, 2004, p. 261), combatendo-a por isso em várias obras ao longo da sua carreira tanto no início (GREELEY, 1969, 1972a/b) como no final (GREELEY, 2003). Para Greeley (2001, p. 36), a maioria dos cientistas sociais considera que a religião não pode sobreviver numa era de razão e de ciência, tornando dogma e norma a lei social do declínio religioso, não podendo ser assim refutada. Porém, a religião perdura, pois as pessoas precisam de acreditar e de pertencer. Nesta perspectiva, Greeley (2001, p. 37) prevê o seguinte futuro religioso nos EUA: a religião não perderá os seus membros nem a sua influência nas outras esferas sociais, as instituições religiosas e as congregações locais não desaparecerão, acolher-se-á outras tradições religiosas, aumentar-se-á a centralidade do indivíduo, as denominações continuarão a ser centrais no espaço religioso. Curiosamente estas previsões foram feitas em Greeley (1969), mantendose passados trinta anos.

Berger mudou de posição em relação à secularização, abandonando a velha teoria, por a considerar incapaz de responder às evidências empíricas de diferentes partes do mundo (BERGER, 2001, p. 445). Como refere Berger (2008, p. 23) a modernidade não é necessariamente secularizadora, no sentido do declínio religioso, mas é necessariamente pluralizadora, no sentido de promover crescente pluralidade de crenças, valores e cosmovisões. Porém, esta foi sempre a sua posição inicial (BERGER, 1990/1967), quando realçava a importância da pluralização. Para 
Berger (2001, p. 445), o mundo continua religioso como sempre foi e em algumas partes é mais religioso do que antes. O ressurgimento religioso actual tem ocorrido sobretudo através do Islão, no mundo muçulmano e na diáspora, e do protestantismo evangélico, especialmente na sua versão pentecostalista, em várias partes do mundo em desenvolvimento, sobretudo a América Latina (BERGER, 2001, p. 445; 2008, p. 23). Contudo, noutras religiões ocorrem revitalizações como no catolicismo, sobretudo nos países em desenvolvimento, no cristianismo ortodoxo, nomeadamente na Rússia, no judaísmo, em Israel e na diáspora, no hinduísmo e no budismo, tendo este tido algum sucesso em apostolar na América e na Europa (BERGER, 2001, p. 445, 2008, p. 23-24). Para Berger (2008, p. 24), a modernidade caracteriza-se não pela ausência de Deus mas pela presença de vários deuses, havendo duas excepções: a Europa Ocidental e Central, a chamada eurosecularidade, cujas causas e formas constituem dos problemas mais interessantes da sociologia da religião; a elite intelectual, no fundo a globalização da intelectualidade iluminista europeia, que, apesar de pequena, tem enorme influência.

Casanova (1994, p. 3-6, 218-219), no seu estudo da religião pública, na linha de Durkheim, assente na ideia de que nos anos 1980 vários conflitos políticos tinham subjacente a religião, advoga a deprivatização religiosa, ou seja, a recusa das tradições religiosas em aceitar o papel marginal e privatizado que as teorias da modernidade e da secularização lhes reservavam. A tipologia usada baseia-se na divisão tripartida do regime democrático moderno em estado, sociedade política e sociedade civil, cada um com a sua esfera pública e com possibilidade de ter religiões públicas. Ao nível do estado, encontram-se as igrejas de estado estabelecidas (Espanha) ou as igrejas nacionais à procura de estado (Polónia). Ao nível da sociedade política, apresentam-se os movimentos religiosos contrários ao fim das religiões oficiais (catolicismo espanhol contra a revolução liberal e as duas repúblicas) e à diferenciação das esferas seculares (cruzadas protestantes para cristianizar as leis norte-americanas); as mobilizações de grupos religiosos e partidos confessionais contra outras religiões ou movimentos e partidos seculares 
(Acção Católica em Espanha, Liga Eleitoral Católica no Brasil, partidos democratas-cristãos); grupos religiosos na defesa da liberdade religiosa (mobilização católica na Polónia comunista); grupos religiosos na defesa do estado de direito e dos direitos humanos e civis ou protegendo a mobilização da sociedade civil e defendendo a institucionalização de regimes democráticos (igrejas católicas de Espanha, Brasil e Polónia). Ao nível da sociedade civil, distinga-se a existência de religiões civis hegemónicas ( protestantismo evangélico nos EUA no século XIX) da intervenção pública de grupos religiosos ( movimentos anti-aborto ou cartas pastorais de bispos católicos).

\subsection{Teorias histórico-culturais}

Este conjunto de teorias descende da linha germânica subjectivista, hermenêutica ou compreensiva, onde o sentido da acção tem de ser olhado na perspectiva individual, neste caso nacional ou regional, e não na perspectiva colectiva, leia-se condicionada pela narrativa hegemónica da modernização única, o que conduz ao domínio das histórias particulares e do sentido ou caminho que a modernização tomou em cada estado ou região. Esta visão multipolar já era encarada na Idade Média em autores como Robert Grosseteste (1175-1253), fundador da Escola de Oxford (Bacon, Escoto, Ockham), franciscana, de matriz platónica e agostiniana, que, para além da sua concepção matemática e experimental da ciência, marcou o pensamento científico com o seu conceito de multiverso em oposição a universo, ou seja, na possibilidade de existência de vários universos no mesmo espaço-tempo. Desta linha descende a concepção de mónadas de Leibniz (1646-1716), mundos separados, todos diferentes, que se regem pela sua própria natureza mas em que o conjunto se harmoniza, sendo essencial para o surgimento do individualismo (RUSS, 1997, p. 156-157). Leibniz influenciou o pensamento de Kant, e assim o idealismo alemão, mesmo que mais tarde este o tenha criticado. Nesta linha enquadra-se a concepção de múltiplas modernidades de Eisenstadt (1923-2010) correspondentes a múltiplas secularizações, pelo cumprimento diverso do programa da modernidade. O hiper-relativismo e o hiper- 
individualismo da sociedade actual conduziram inevitavelmente as ciências sociais para a contextualização das teorizações e das análises empíricas, tornando paulatinamente desajustados quaisquer estudos generalistas. Deste subgrupo apresenta-se primeiro David Martin (1929), herdeiro intelectual de Weber (MARTIN, 2005: 11), pela sua obra pioneira desde os anos 1960 (MARTIN, 1969, 1978, 2005, 2011). De seguida, aparecem Philip Gorski (1963) e Charles Taylor (1931), ambos seguidores de Martin.

Martin (2005, p. 20) desenvolve a sua teoria da secularização assente no processo de diferenciação social descrito por Parsons, para quem esta não era tomada como declínio, mas antes como oportunidade para a religião alcançar melhor a sua função, nomeadamente através do pluralismo religioso. Focado no cristianismo, Martin (2005, p. 20-21, 58-59) analisa o processo de diferenciação social através de três filtros históricos, cruciais para conduzir a secularização em direcções singulares, destacando-se o tipo de cristianismo e a região onde se implanta (protestantismo ou catolicismo; Europa ou América) e o tipo de regulação religiosa (pluralismo ou monopólio), havendo ainda a questão centro/periferia, associada ao nacionalismo religioso. Como refere Taylor no prefácio de Martin (2005), este autor trouxe duas alterações à discussão sobre a secularização. Na primeira, de cariz hermenêutico, em vez de mostrar como a modernidade levou à secularização de forma universal e única, evidenciou a pluralidade de secularizações em diferentes países e culturas. Martin (2011, p. 26-27) considera que, apesar de os grandes processos históricos (racionalização) terem alguma verdade neles, não podem ser tomados de forma linear mas antes escrutinados à luz da história particular de cada país ou região, dando origem a secularizações singulares. Na segunda, de cariz dialéctico, que suporta a anterior, em vez de olhar para a história composta de ganhos e perdas irreversíveis, trouxe a noção de que a história se vai construindo, com avanços e recuos, podendo os ganhos actuais terem perdas futuras e vice-versa. Como explica Martin (2005, p. 11-12), a dialéctica histórica assenta na tensão entre a visão transformadora cristã de paz e harmonia e as realidades sociais de poder e violência, acima de tudo, mas também 
nas tensões entre a beleza artística e o erotismo, ou entre a generosidade e a mutualidade contra o prazer e o lucro.

Gorski (2003) revisitou a posição teórica de Martin relativamente ao pluralismo religioso, denominando-a como modelo do conflito sócio-político, em alternativa à teoria da secularização clássica e ao modelo das economias religiosas. Para Gorski (2003, p. 116-118), este modelo apresenta as seguintes vantagens em relação ao modelo económico: explica a diminuição da vitalidade religiosa associada ao maior pluralismo religioso e à menor regulação estatal, a maior vitalidade do catolicismo contemporâneo e a variabilidade da vitalidade religiosa dentro de cada bloco católico e protestante; além disso explica a secularização ao nível macro, como luta entre movimentos religiosos e seculares pelo controlo de determinados sectores ou instituições (educação e escolas), algo ignorado pelo modelo das economias religiosas e desenvolvido vagamente pela teoria clássica. Apesar destas vantagens, este modelo não consegue responder às questões sobre as tendências históricas e as raízes dos conflitos sociopolíticos, para os quais Gorski (2003, p. 118-120) deixa algumas sugestões. Para o primeiro caso, sugere registar a evolução da prática cristã e da autoridade eclesiástica, através de estudos históricos de longo prazo, alertando para que variações na prática religiosa não significam necessariamente mudanças na religiosidade individual, podendo ser causadas por factores sociais ou por mudanças na qualidade da religiosidade colectiva. Para o segundo caso, sugere revisitar os clássicos Durkheim e Weber, que apresentam propostas complementares: o primeiro para explicar a razão da separação das esferas religiosas das não religiosas, o segundo para estudar os actores que a produzem.

Taylor (2012, p. 13-16) começa por afirmar que é unânime considerar-se que se vive numa era secular no Atlântico Norte e noutras partes do globo, embora de maneira parcial e com formas diferentes, o que vai ao encontro das múltiplas modernidades. Para ele, a questão coloca-se não na existência de secularidade, mas 
no seu significado: concorda com dois tipos de secularidade habitualmente referidos pela sociologia, mas acrescenta uma nova perspectiva à mesma. No primeiro tipo encontra-se a privatização, em que menciona o esvaziamento dos espaços públicos de Deus ou da referência a alguma realidade última. A este processo associa-se a diferenciação e a autonomização, em que as várias esferas de actividade (económica, política, etc.) são regidas por normas próprias isentas de ligações a Deus ou a crenças religiosas. No segundo tipo apresenta-se o declínio de crenças e práticas, no alheamento de Deus e dos rituais litúrgicos. Taylor avança com um terceiro tipo, estreitamente relacionado com o anterior e não sem ligação ao primeiro: as condições da fé. Neste tipo, a mudança para a secularidade caracterizar-se-ia por uma “[...] passagem de uma sociedade em que a fé em Deus é não contestada e, de facto, não problemática, para uma sociedade em que a fé é entendida como uma opção entre outras [...]”. O que lhe interessa é entender as diferenças nas formas e nas condições de acreditar, pois, mesmo que haja similitudes no segundo tipo, no terceiro tipo podem diferir.

A postura epistemológica assente na concepção teórica das múltiplas modernidades tem atravessado muitos autores, nomeadamente Casanova e Davie, tratados noutra secção. Casanova (2007, p. 105-120) revê as suas posições teóricas iniciais (CASANOVA, 1994): a diferenciação decorre do dualismo mundo/religião, por isso ocorre somente no mundo ocidental, variando com a tradição religiosa; não há declínio mas transformação da religião, na medida em que as religiões vão assumindo novas formas nos três níveis (individual, organizacional e societal); continua a assistir-se a situações de reversão da privatização em todas as tradições religiosas e nos vários sistemas políticos de todo o mundo. A modernidade ocidental, já pós-cristã, pode globalizar-se mas terá de interagir e reformular-se no contacto com os padrões civilizacionais não ocidentais, por um lado; as múltiplas modernidades não ocidentais, já pós-civilizacionais também, já são transformações modernas dos padrões anteriores, por outro lado (CASANOVA, 2013, p. 265, 278279). Davie (2002), à revelia das teorias da secularização, propõe a excepcionalidade da Europa, sendo o único caso em que a modernização e a 
secularização (declínio) correspondem. Nos outros casos, focados no cristianismo, EUA, América Latina, África subsaariana e Extremo Oriente, à modernização está associado o crescimento religioso. Conclui-se assim que não se pode adoptar um modelo único europeu para avaliar as outras realidades religiosas, já que a modernidade toma diferentes formas ao sabor dos contextos histórico-culturais específicos de cada país ou região. Ela reforça esta posição em Davie (2004, p. 83) referindo que os sociólogos têm de encontrar novas abordagens para compreender a religião no mundo moderno, tanto dentro como fora da Europa.

\section{Conclusão}

A ambiguidade da sociologia de Durkheim e Weber em relação ao futuro da religião, que marcou profundamente os clássicos da secularização, apresenta-se nas teorias actuais, suas sucessoras, pela existência de dois grupos quase opostos de teorias. Estes grupos, divididos em adeptos e adversários, distinguem-se sobretudo pela forma como olham para a instituição religiosa: para os primeiros, ela encontra-se em erosão, para os segundos, afigura-se viva. A forma como as teorias se emparelham também expressa esta dualidade: às teorias pós-clássicas, adeptas, opõem-se as teorias do regresso, adversárias, ambas presentes nos três níveis; às teorias da individualização, adeptas, de religiosidade individual, opõe-se o modelo económico, adversário, de religiosidade institucional, ambos focados no nível micro (embora o último também trate do nível meso). As teorias histórico-culturais poderiam eventualmente constituir um terceiro grupo, tal como sugere Beck (2010, p. 39). Todavia, o seu pioneiro, Martin, sempre foi acérrimo contraditor das teorias clássicas, daí a sua pertença ao grupo dos adversários.

Weber e Durkheim representam duas grandes correntes epistemológicas europeias: de um lado, a linha germânica idealista; do outro lado, a linha latina racionalista. Weber só não está presente no modelo económico. Nas teorias pósclássicas, salienta-se a racionalização como motor da secularização, com profunda influência em Wilson e Berger, cujas concepções estão inclusas nas propostas 
teóricas deste grupo (Tschannen e Dobbelaere) ou as influenciaram (Bruce). Nas teorias da individualização, a bricolage surge em Luckmann, desenvolvido primeiro em Dobbelaere e depois por Hervieu-Léger, sendo bastante influenciado pela questão do sentido de Weber. Nas teorias do regresso, surge novamente a religião como fornecedora de sentido (Bell, Greeley) e a pluralização como resultado da racionalização (Berger). Nas teorias histórico-culturais, emerge a questão das análises comparativas histórico-culturais (Martin, Gorski, Taylor, Davie, Casanova). Em resumo, a racionalização, o sentido e a análise histórico-cultural são os três principais legados às teorias da secularização. Esta herança insere-se na linhagem idealista, subjectivista e compreensiva alemã: a racionalização como ideal tipo que compreende a modernidade, o sentido como forma subjectiva subjacente à acção, a análise histórico-cultural como processo compreensivo.

Durkheim está presente em todas as teorias. A diferenciação é usada nas teorias pós-clássicas como motor da secularização para Luckmann; no modelo económico como promotora da religião para Parsons; nas teorias históricoculturais na vertente anterior condicionada pelo contexto nacional para Martin. A religião como garantia da ordem social é usada nas teorias da individualização (Hervieu-Léger), no modelo económico (Parsons) e nas teorias do regresso (Casanova). A bricolage de Luckmann também é bastante influenciada pela questão da diferenciação como geradora de formas privatizadas de religião para Durkheim (Hervieu-Léger). A esta posição pode associar-se a conceptualização de Inglehart sobre autonomia pessoal, acima referida, que assenta ainda em Durkheim e na dicotomia solidariedade mecânica/solidariedade orgânica. A religião como memória, associada às linhagens crentes, também usada nas teorias da individualização (Hervieu-Léger, Davie) assenta nas representações colectivas de Durkheim. Em resumo, a diferenciação (embora com desenlaces opostos: privatização/bricolage e pluralização), a ordem social garantida pela religião e a relação do individual com o colectivo (memória colectiva, linhagens crentes) são os três principais legados às teorias da secularização. Esta herança insere-se na linhagem positivista, colectivista e explicativa francesa: a ordem e o colectivo como 
expressão desta ênfase colectivista, a diferenciação como processo explicativo da modernização em formato causa/efeito.

A escola alemã, marcada pelo idealismo, com Tönnies, Simmel, Troeltsch e também James distingue sobretudo as teorias da individualização. A conceptualização de Inglehart sobre autonomia pessoal assenta em Simmel na diversificação das relações sociais e em Tönnies na dicotomia comunidades/sociedades, esta também usada por Wilson (societalização) e pelas teorias pós-clássicas. A abordagem de Heelas encontra-se influenciada pelas definições de religiosidade de Simmel e de misticismo de Troeltsch, e de Roof pela análise tipológica de James. Esta individualização no nível micro pode ser comparada à 'individualização' no nível macro, referente às múltiplas modernidades defendidas pelas teorias histórico-culturais, tendo como referencial comum o subjectivismo alemão. Por sua vez, as teorias histórico-culturais e o modelo económico apresentam pontos comuns. Primeiro, partilham ascendência anglo-saxónica: as primeiras derivam do idealismo alemão, influenciado por Leibniz, por sua vez influído pela Escola de Oxford; o segundo foi marcado pelo empirismo britânico, através de Smith e Mil. Segundo, em ambos a pluralização (nível meso) é muito importante para explicar o desempenho religioso. O modelo económico sofre ainda influência do racionalismo latino pelo marginalismo (Pareto, Parsons, Homans).

\section{REFERÊNCIAS}

ALDRIDGE, A. Religion in the contemporary world: a sociological introduction. Cambridge: Polity Press, 2000.

AZZI, C; EHRENBERG, R. Household allocation of time and church attendance. Journal of Political Economy, v. 83, n. 1, p. 27-56, 1975.

BECK, U. A God of one's own. Cambridge: Polity Press, 2010/2008.

BELL, D. The return of the sacred? The argument on the future of religion. British Journal of Sociology, v. 28, n. 4, p. 419-449, 1977. 
BELLAH, R.N. Civil religion in America. In: BELLAH, R.N. (Ed.). Beyond belief: essays on religion in a post-traditional world. New York (NY): Harper \& Row, 1967, p. 168189.

BERGER, P.L. Reflections on the sociology of religion today. Sociology of religion, v. 62, n. 4, p. 443-454, 2001.

BERGER, P.L. Sacred canopy: elements of a sociological theory of religion. New York (NY): Anchor Books, 1990/1967.

BERGER, P.L. Secularization falsified. First things: A monthly Journal of Religion \& Public Life, v. 180, p. 23-27, 2008.

BRUCE, S. God is dead: secularization in the West. Malden (MA): Blackwell Publishing, 2002.

BRUCE, S. Religion in the modern world: from cathedral to cults. Oxford: Oxford University Press, 1996.

CASANOVA, J. A secular age: dawn or twilight? In: WARNER, M; VANANTWERPEN, J.; CALHOUN, C. (Eds.). Varieties of secularism in a secular age. Cambridge (MA): Harvard University Press, 2013, p. 265-281.

CASANOVA, J. Public religions in the modern world. Chicago (IL): Chicago University Press, 1994.

CASANOVA, J. Rethinking secularization: a global comparative perspective. In BEYER, P.; BEAMAN, L. (eds.). Religion, globalization and culture. Leiden: Koninklijke Brill NV, 2007, p. 101-120.

CHAVES, M. Secularization as declining religious authority. Social Forces, v. 72, n. 3, p. 749-774, 1994.

CIPRIANI, R., Manual de sociología de la religión. Buenos Aires: Siglo veintiuno editores Argentina, 2004/1997.

DAVIE, G. Religion in Britain: a persistent paradox. Oxford: Wiley-Blackwell, 2015.

DAVIE, G. Europe: the exceptional case. Parameters of faith in the modern world. London: Darton, Longman and Todd, 2002.

DAVIE, G. Is Europe an exceptional case? International Review of Mission, 95 (378/379), p. 247-258, 2006.

DAVIE, G. New approaches in the sociology of religion: A Western perspective. Social Compass, v. 51, n. 1, p.73-84, 2004.

DAVIE, G. Religion in Britain since 1945: believing without belonging. Oxford: Blackwell, 1994. 
DAVIE, G. Religion in modern Europe: a memory mutates. Oxford: Oxford University Press, 2000.

DOBBELAERE, K. Towards an integrated perspective of the processes related to the descriptive concept of secularization. Sociology of Religion, v. 60, n. 3, p. 229-247, 1999.

DOBBELAERE, K. Trend report: Secularization: a multi-dimensional concept. Current Sociology, v. 29, n. 2, p. 3-153, 1981.

DURKHEIM, É. The elementary forms of religious life. Oxford: Oxford University Press, 2001/1912.

FENN, R.K. The process of secularization: a post-Parsonian view. Journal for the Scientific Study of Religion, v. 9, n. 2, p. 117-136, 1970.

FINKE, R.; STARK, R. How the upstart sects won America: 1776-1850. Journal for the Scientific Study of Religion, v. 28, n. 1, p. 27-44, 1989.

GORSKI, P.S. Historicizing the secularization debate. In: DILLON, M. (Ed.). Handbook of the sociology of religion. Cambridge: Cambridge University Press, 2003, p. 110-122.

GREELEY, A. Religion in Europe at the end of the second millennium. New Brunswick (NJ): Transaction Publishers, 2003.

GREELEY, A. Religion in the year 2ooo. New York (NY): Sheed and Ward, 1969.

GREELEY, A. The denominational society: a sociological approach to religion in America. Glenview (IL): Scott, Foresman \& Co, 1972a.

GREELEY, A. The future of religion in America. Society, March/April, p. 32-37, 2001.

GREELEY, A. Unsecular man: the persistence of religion. New York (NY): Schocken Books, $1972 b$.

HALBWACHS, M. La mémoire collective. Paris: PUF, 1950.

HEELAS, P. Spiritualities of life: romantic themes and consumptive capitalism. Oxford: Blackwell, 2008.

HEELAS, P. The New Age movement. Oxford: Blackwell, 1996.

HEELAS, P.; WOODHEAD, L. The spiritual revolution: why religion is giving way to spirituality. Oxford: Blackwell, 2005.

HERVIEU-LÉGER, D. O peregrino e o convertido: a religião em movimento. Lisboa: Gradiva, 2005/1999. 
HERVIEU-LÉGER, D. Religion as a chain of memory. New Brunswick (NJ): Rutgers University Press, 2000/1993.

IANNACCONE, L.R. Religious markets and the economics of religion. Social Compass, v. 39, n. 1, p. 123-131, 1992.

IANNACCONE, L.R. The consequences of religious market structure: Adam Smith and the economics of religion. Rationality and Society, v. 3, n. 2, p. 156-177, 1991.

IANNACCONE, L.R. Voodoo economics? Reviewing the rational choice approach to religion. Journal for the Scientific Study of Religion, v. 34, n. 1, p. 76-89, 1995.

INGLEHART, R.; WELZEL, C. Modernization, cultural change, and democracy: the human development sequence. New York (NY): Cambridge University Press, 2005.

KENNY, A. História concisa da filosofia ocidental. Lisboa: Temas e Debates, $1999 / 1998$.

LUCKMANN, T. The invisible religion: the problem of religion in modern society. London: The Macmillan Company, 1970/1967.

MARKULY, M. Wade Clark Roof. Spiritual marketplace: baby boomers and the remaking of American religion (Book review). Journal of Religion \& Society, v. 4, 2002.

MARTIN, D. A general theory of secularization. Oxford: Blackwell, 1978.

MARTIN, D. Notes towards a general theory of secularisation. European Journal of Sociology, v. 10, n. 2, p. 192-201, 1969.

MARTIN, D. On secularization: towards a revised general theory. Aldershot: Ashgate, 2005 .

MARTIN, D. The future of Christianity: reflections on violence and democracy, religion and secularization. Farnham: Ashgate, 2011.

MARTIN, D. The religious and the secular: studies in secularization. London: Routledge \& Kegan Paul, 1969.

NORRIS, P.; INGLEHART, R. Sacred and secular: religion and politics worldwide. Cambridge: Cambridge University Press, 2004.

PARSONS, T. Christianity and modern industrial society. In: TIRYAKIAN, E.A. (ed.). Sociological theory, values, and sociocultural change: essays in honor of Pitirim A. Sorokin. New York (NY): Harper \& Row, 1963, p. 33-70.

PARSONS, T. Religious perspectives of college teaching in sociology and social psychology. New Haven (CT): The Edward W. Hazen Foundation, 1952. 
POLLACK, D.; MULLER, O.; PICKEL, G. (Ed.) The social significance of religion in the enlarged Europe: Secularization, individualization and pluralisation. Farnham: Ashgate, 2012.

ROOF, W.C. A generation of seekers: the spiritual journeys of the baby boom generation. New York: Harper Collins, 1993.

ROOF, W.C. Spiritual marketplace: baby boomers and the remaking of American religion. Princeton: Princeton University Press, 1999.

RUSS, J. A aventura do pensamento europeu: uma história das ideias ocidentais. Lisboa: Terramar, 1997/1995.

SCOTT, J. Sociological theory. Contemporary debates. Cheltenham: Edward Elgar Publishing, 1997/1995.

SMITH, A. The wealth of nations. Part three. New York: P.F. Collier \& Son, 1902/1776.

STARK, R.; BAINBRIDGE, W.S. A theory of religion. New Brunswick (NJ): Rutgers University Press, 1996/1987.

STARK, R.; FINKE, R. Acts of faith. Berkeley and Los Angeles (CA): University of California Press, 2000.

TAYLOR, C. A era secular. Lisboa: Instituto Piaget, 2012/2007.

TOCQUEVIlle, A. Da democracia na América. Lisboa: Relógio d’Água, 2008/1835.

TSCHANNEN, O. La genèse de l'approche moderne de la sécularisation : une analyse en histoire de la sociologie, Social Compass, v. 39, n. 2, p. 291-308, 1992.

TSCHANNEN, O. The secularization paradigm: a systematization. Journal for the Scientific Study of Religion, v. 30, n. 4, p. 395-415, 1991.

WARNER, R. Secularization and its discontents. London: Continuum International Publishing Group, 2010.

WILLAIME, J.-P. La sécularisation: une exception européenne? Retour sur un concept et sa discussion en sociologie des religions. Revue Française de Sociologie, v. 47, n. 4, p. 755-783, 2006.

WILSON, B. Religion in secular society: a sociological comment. London: C.A. Watts, 1966.

YAMANE, D. Secularization on trial: in defense of a neosecularization paradigm. Journal for the Scientific Study of Religion, v. 36, n. 1, p. 109-122, 1997. 